\begin{tabular}{|c|c|c|c|c|c|}
\hline MUNIBE Antropologia-Arkeologia & $n^{\circ} 68$ & $273-288$ & DONOSTIA & 2017 & ISSN 1132-2217 • eISSN 2172-4555 \\
\hline
\end{tabular}

\title{
Los dados de Ausa y Mendikute (s. XIII-XIV): La elaboración de objetos lúdicos en hueso en algunas fortificaciones medievales del territorio guipuzcoano
}

\section{Dice from Ausa and Mendikute (13 $14^{\text {th }}-14^{\text {th }}$ Centuries): The elaboration of bone game pieces in some medieval fortresses from Gipuzkoa}

PALABRAS CLAVES: Castillos, industria ósea, juego, dados.

GAKO-HITZAK: Gazteluak, hezur-industria, jolasa, dadoak.

KEY WORDS: Castles, bone productions, game, dice.

\author{
Karen ALVARO(1), Esther TRAVÉ(1) y M. Dolores LÓPEZ(1)
}

\section{RESUMEN}

El estudio arqueológico de los recintos fortificados de Ausa y Mendikute permitió recuperar una muestra significativa de útiles y complementos óseos correspondientes a la fase final de su ocupación militar. Entre los objetos elaborados en hueso, cabe destacar un conjunto de piezas de carácter lúdico, mayoritariamente dados, así como otros elementos residuales del proceso de elaboración. Dichos testimonios avalan que se trata de una manufactura local realizada por la soldadesca de ambas fortificaciones fronterizas.

\section{LABURPENA}

Ausako eta Mendikuteko esparru gotortuen ikerketa arkeologikoaren bidez, haren okupazio militarraren amaierako faseko hezur-osagarri eta tresnen lagin esanguratsua berreskuratu ahal izan da. Hezurrarekin egindako objektuen artean, izaera ludikoko piezen multzoa (batez ere dadoak) eta prestaketa-prozesuko hondakin-elementu batzuk nabarmendu behar dira. Testigantza horiek agerian utzi dute bi gotorleku mugakideetako soldaduek bertan egindako manufaktura direla.

\section{ABSTRACT}

The archaeological study of the medieval fortresses of Mendikute and Ausa allowed discovering a significant sample of bone tools and accessories from the final phase of their military occupation. Among these objects made of bone, a set of game pieces mostly including dice has been studied together with other elements related to the manufacturing process. Such evidences suggest that these manufactures where local productions made by the soldiers of both border fortifications. The study presented throughout these paper aims at offering a new data for the increasing of the state-of-the-art with regard to medieval games and leisure activities.

The fortresses of Mendikute (Albiztur, Gipuzkoa) and Ausa (Zaldibia, Gipuzkoa) are set upon the southern area of the historical Gipuzkoan landascape, on the Upper Oria Basin, where the flows of rivers Goierri and Tolosaldea join together. Both fortresses exhibit high similarities with regard to their function, architecture and inner layout. These parallels suggest a most likely coetaneous building within the implantation process of the Navarre kingdom in the Basque Country.

The archaeological materials studied were found at the occupation and destruction layers at both fortresses. The entire assemblage is formed by a set of bone dice and some auxiliary elements for their fabrication. These are bone prismatic bars ready for dice-cutting, bone cubes already cut and prepared for point marking and some remains of scrapped bones where prismatic bars were so far obtained.

The most interesting aspect of these materials is the punctuation of dice, which mostly follows the late medieval convention placing 1 opposite to 6, 2 opposite to 5, and 3 opposite to 4 . While this is the normal rule in most individuals, one dice from Mendikute (MEN 525) exhibits wrong punctuation in the form $1 / 6,2 / 3,4 / 5$. This is not an isolated phenomenon, as some other parallels of erratic punctuation are known, even if they are not tricky dice. Examples of erratic punctuation are those that do not follow the normal rules, but there is no deceit in their fabrication. The found of auxiliary elements for dice fabrication, which points towards the local production of Ausa and Mendikute's dice, has also other parallels in the nearby area, the Iberian Peninsula, Southern France or Great Britain, as demonstrated throughout this piece of research.

The process of dice fabrication and their chronology are discussed according to the archaeological and written sources. Archaeological evidence reveals that most of these elements were made of bone, whilst this material is not exclusive as many others are known, such as wood, ivory or stone. The Alphonse X's Book of Games shows some activities related to dice fabrication beautifully represented in its illuminations. The book itself offers remarkable information about the prescriptions and rules for the placement of the punctuation onto the cubes in late Middle age, which is slightly different from the majoritarian one in ancient times.

To sum up, the study of medieval dice needs a holistic approach including written and archaeological evidence to determine the production processes and rules for game practices. Bone dice found at the medieval fortresses of Ausa and Mendikute, together with the remains of their fabrication, provide some evidence for their local production, probably made by soldiers guarding the border and aiming at amusing themselves in their leisure time.

\footnotetext{
(1) Grup de recerca d'arqueologia medieval i postmedieval. (2017SGR-833-GRC). Dept. d'Història i Arqueologia. Universitat de Barcelona. E-mail: kalvaro@ub.edu; esther.trave@ub.edu; mdlopez@ub.edu.
} 


\section{1.- INTRODUCCIÓN}

Este trabajo aborda el estudio de un pequeño número de objetos óseos vinculados al juego en algunas guarniciones del territorio guipuzcoano. Nos referimos a un conjunto de doce dados procedentes de las fortalezas de Ausa y Mendikute, junto con otros testimonios de fabricación que avalan la manufactura de dichos elementos: cubos regulares ya tallados pero sin puntuación y regletas o listones de hueso trabajados como preforma para la preparación de los cubos. Esta materia resistente, pero asequible y de fácil labra, ha permitido obtener piezas de aspecto y tacto agradable, que han resistido bien el paso del tiempo gracias a su naturaleza perdurable. Entre el conjunto de dados, se advierten peculiaridades relativas a la disposición de la puntuación o el tipo de talla que tendremos ocasión de comentar y que presentan paralelos en otros enclaves franceses e hispanos.

La constatación de esta actividad artesana no representa, en sí misma, ninguna novedad sorprendente, ya que la elaboración de objetos y complementos en hueso aparece ampliamente difundida en época medieval, alcanzando una cierta especialización en la producción de ciertos útiles de uso corriente. En cualquier caso, el conjunto de dados de Ausa y Mendikute constituyen un elemento emblemático y representativo de las actividades de distracción de la soldadesca de ambas fortalezas, que emplean los largos tiempos muertos de vigilancia en un espacio fronterizo al juego.

Este carácter lúdico de los materiales analizados constituye su mayor atractivo a la hora de valorar las implicaciones sociales y económicas de los mismos. Ciertamente el juego es un divertimento e incluso una frivolidad que implica la dedicación de un tiempo a actividades no productivas, por lo que resulta interesante remarcar el carácter aristocrático o elitista de los mismos. Hacer un análisis pormenorizado de las implicaciones socioeconómicas que tiene el juego como tal o la existencia de un tiempo de ocio que escapa de las obligaciones productivas es una propuesta sugerente a la luz de las interpretaciones más novedosas del estudio de la edad media en estos términos, con un marcado carácter socioeconómico (Wickham, 2005).

En cualquier caso, para que este análisis -que definitivamente escapa de los objetivos y alcance de nuestro trabajo- sea verdaderamente efectivo, se precisan de numerosos ejemplos arqueológicos y documentales en un marco territorial amplio que permitan el estudio comparativo. Es decir, la existencia de numerosos estudios de caso, a mayor y menor escala, a fin de proporcionar un conjunto de elementos susceptible de comparación interregional es lo que permite analizar de manera pormenorizada este tipo de fenómenos socieconómicos con connotaciones muy importantes para el conocimiento de la sociedad medieval, huyendo de los modelos generalistas que acaban deviniendo problemáticos cuando se reducen a una escala menor (Wickham, 2004).
En este sentido, la nuestra pretende ser una aportación con un marcado carácter territorial y circunscrita a un espacio concreto, que contribuya a incrementar el número de estos elementos conocidos que deben ser necesariamente comparados, desde una aproximación que permita gestionar de manera integrada las fuentes materiales, documentales e iconográficas. Por todo ello, presentamos los materiales en cuestión en su contexto inmediato, ofrecemos un análisis detallado de sus rasgos y características principales y analizamos los procesos de producción de dados y elementos lúdicos en un marco necesariamente regulado durante los siglos bajomedievales.

\section{LOS MATERIALES ÓSEOS Y SU CONTEXTO}

El conjunto de materiales arqueológicos que analizamos en este trabajo, fue recuperado en los niveles de utilización de los recintos de Mendikute (Albiztur) y de Ausa (Zaldibia). Ambas fortificaciones medievales se emplazan sobre el sector meridional del territorio histórico de Guipúzcoa, en la cuenca del medio y alto Oria, sobre el área de confluencia del Goierri y Tolosaldea (Beterri). La gran similitud existente entre ambas guarniciones puede quedar enmascarada a primera vista ante las particularidades que ofrece cada recinto, pero un análisis más ponderado revela que ambos castillos roqueros presentan mutuas semejanzas tanto en su disposición espacial como en su planificación interna. Las afinidades existentes entre ambos yacimientos nos llevan a pensar que las dos fortificaciones formaron parte de una misma concepción arquitectónica y, tal vez, de una misma empresa constructiva que correspondería al proceso de implantación que la monarquía navarra desarrolla de modo efectivo sobre este territorio (Padilla, 2010: 474-475).

En cualquier caso, el diseño y planificación de estas guarniciones constituye un buen paradigma del tipo de fortificación altomedieval que llegó a prosperar a ambos lados del espacio fronterizo con el reino navarro. El tamaño reducido de sus defensas, así como la composición y disposición de sus cuerpos defensivos y estructuras representativas, reflejan con bastante exactitud los planteamientos adoptados en fortificaciones coetáneas de otros territorios europeos, como las conocidas motas o los recintos fortificados en altura de morfología similar (motte d'éperon). Una analogía demasiado evidente que nos ayuda a fijar la secuencia fundacional de ambas fortificaciones, que serían remodeladas y reconstruidas en varias ocasiones a lo largo de su existencia.

Ambos centros fueron excavados por nuestro equipo en el marco de un proyecto de investigación arqueológica titulado "Reorganización del espacio y estructura del poblamiento en la cuenca alta del río Oria (ss. XI-XIII)", que tuvo por objetivo abordar el estudio arqueológico de dos fortificaciones de época medieval -Ausa y Mendikute- de dimensiones y características similares 
a otros conjuntos presentes en la misma área territorial (Fig. 1).

La primera fortaleza en ser intervenida fue la de Mendikute (Albiztur, Guipúzcoa) a lo largo de los años 90. Las tareas de excavación pusieron de manifiesto que el yacimiento había sufrido severas afectaciones durante la primera mitad del siglo XX, que alteraron notablemente los contextos medievales. Tanto las excavaciones tempranas llevadas a cabo a principios de siglo por López Mendizábal (Padilla, 1992: 2017; López Mendizábal, 1959), como la reutilización militar del emplazamiento entre 1936 y 1937 durante la Guerra Civil alteraron en parte la estratigrafía del yacimiento y acabaron por modificar considerablemente el depósito arqueológico. A ello debe añadirse el estado precario de las estructuras murarias que -tal como sucede en Ausa- se adaptan a las floraciones rocosas sobre las que se asientan.

La excavación arqueológica de Mendikute planteó, pues, ciertas incógnitas que sólo eran posibles de solventar a partir del estudio de una nueva fortificación coetánea que reuniera los elementos constructivos básicos y unas condiciones estratigráficas adecuadas. En este sentido se iniciaron en 1998 los trabajos arqueoló- gicos en el yacimiento de Ausa (Zaldibia, Guipúzcoa). En este caso, los niveles estratigráficos no parecen haber sido afectados por remociones importantes de época contemporánea, a excepción hecha de la prospección realizada en 1916 por J. Mª Barandiarán (PadiIla, 1999: 108). Además, las referencias documentales existentes precisan los elementos estructurales y reparaciones efectuadas en el recinto durante la etapa final de la guarnición, informando también sobre la nómina de los alcaides que detentaron la fortaleza.

Ausa presenta un cuerpo constructivo principal, cuyo trazado se encuentra condicionado a las características de los afloramientos naturales y situado sobre un promontorio de difícil acceso. Esta estructura se divide en dos recintos que corresponden a ámbitos complementarios: un recinto superior o noble, que probablemente contó -igual que Mendikute- con un único perímetro murado y un recinto inferior de superficie triangular que defiende el espacio superior y los puntos más vulnerables del recinto, a los pies del cual parece localizarse una cisterna. Una rampa suave de acceso con peldaños permite acceder por la parte sur hasta el recinto superior, de planta probablemente cuadrada. Destaca el lienzo de muro de la cara septentrional de

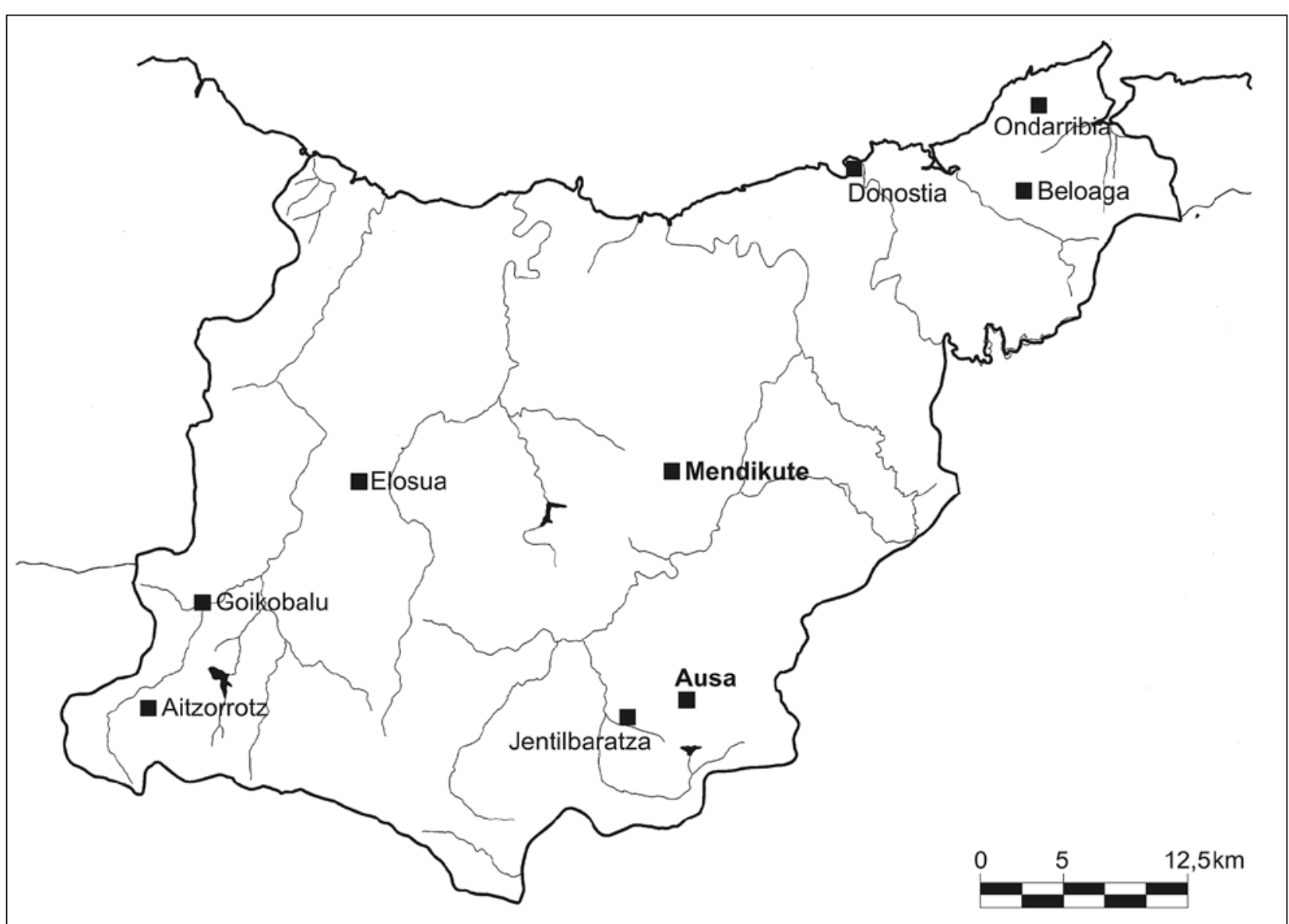

Fig. 1. Mapa de la provincia de Gipuzkoa con la localización de las fortalezas medievales, entre las que se cuentan los yacimientos de Ausa y Mendikute. / Map of the province of Gipuzkoa where the medieval fortresses of Ausa and Mendikute among others are located. 
1,80 m de espesor. En el centro, y en el lugar preeminente del recinto, se encuentra una torre circular de 6,60 m. de diámetro, con muros que ostentan un grosor medio de $1,70 \mathrm{~m}$, que pervivió a las diversas reparaciones que documentamos en la edificación y que constituye un elemento esencial en la organización interna del edificio.

Esta estructura aparece de manera análoga en Mendikute, en donde la fortificación medieval se asienta en la cumbre del monte homónimo. El espacio fortificado, de dimensiones reducidas, presenta también un doble recinto a cota diferenciada: un espacio inferior guarnecido con baluartes defiende los accesos a la fortificación cuyo cuerpo principal descansa sobre una plataforma más elevada. Este recinto superior, de planta heptagonal irregular, con un pronunciado ángulo hacia el oeste se adapta al perímetro rocoso y cuenta con muros de mampostería con sillarejo aparejado en ambas caras en hiladas horizontales. También esta estruc- tura cuenta con la presencia de un ámbito rectangular excavado en la roca, de más de $2 \mathrm{~m}$ de profundidad y con una capacidad de casi $17 \mathrm{~m}^{3}$ que interpretamos también como cisterna.

Las intervenciones arqueológicas llevadas a cabo en estos recintos fortificados proporcionaron un volumen considerable de restos faunísticos, hallados fundamentalmente en niveles de utilización y amortización en el caso de Ausa, y en niveles de derrumbe de Mendikute, algo más descontextualizados, a causa de las afectaciones posteriores del yacimiento (Fig. 2). En el caso de Ausa, los niveles más fructíferos se extienden desde la torre del homenaje hasta la muralla en el ámbito norte del recinto, pese a su reducida potencia de tan sólo 10-15 cm. Desconocemos si el depósito que colmata la parte más baja del área cercana al paramento de la muralla pertenece a una aportación intencionada para nivelar una pavimentación del sector o si corresponde a un proceso natural de colmatación durante una etapa
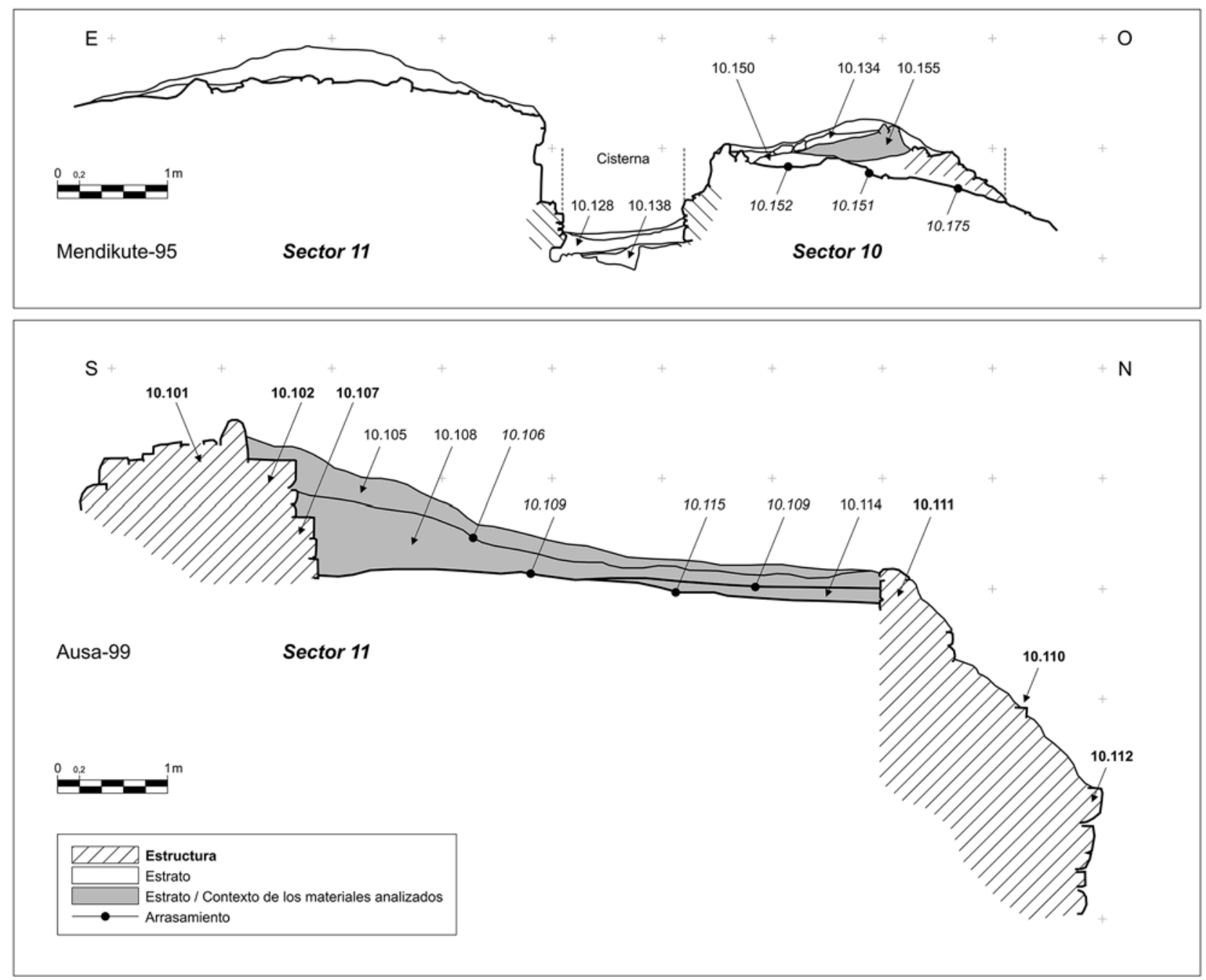

Fig. 2. Secciones de los contextos arqueológicos de los hallazgos. Sección E-O de los sectores 10 y 11 en el yacimiento de Mendikute (arriba) y sección N-S del sector 11 en Ausa (abajo) (Cf. PADILLA, 1999: 111 y 1995: 199; 201)./ Profiles of the archaeological contexts of the findings. Section E-W of trenches 10 and 11 at the site of Mendikute (top), and section N-S of trench 11 at Ausa (bottom) (Cf. PADILLA, 1999: 111 y 1995: 199; 201). 
de abandono. Sea como fuere, se trata de tierras poco compactas que dejan al descubierto un suelo ocasional correspondiente a una fase de abandono durante los trabajos de reconstrucción de la muralla (Padilla, 1999: 112-113).

Los aspectos más precisos sobre estos recintos pueden conocerse a través de los informes sobre las intervenciones en ambos yacimientos (Padilla, 1992-97; Padilla, 1994-04), aunque también conviene tener presente desde una perspectiva más general la reciente síntesis, llevada a cabo partir de la revisión del registro arqueológico, sobre el poblamiento medieval de este territorio (Sarasola, 2011).

Esta cantidad ingente de materiales procede mayoritariamente de residuos alimenticios, que testimonian el consumo de componentes cárnicos que integraban la dieta de la guarnición. Los materiales óseos ofrecen, por lo general, una fragmentación muy elevada no sólo por el proceso de despiece del animal y de su posterior preparación culinaria, sino sobre todo por el deterioro y segmentación postdeposicional sufrida en las actividades posteriores que vinieron a afectar el depósito arqueológico de ambos recintos fortificados. Por ello, el estudio arqueológico de los mismos se llevó a cabo tras el descarte de determinados niveles con fuerte alteración antrópica postdeposicional,

En el caso de Mendikute, el número de elementos óseos representa un $13 \%$ sobre el conjunto de materiales inventariados y constituyen uno de los grupos mayoritarios, por detrás del conjunto de materiales metálicos, que aparecen encabezados por los elementos férreos. En el yacimiento de Ausa, el porcentaje de restos faunísticos seleccionado parece algo menor (4\%) sobre un conjunto inventariado mucho más amplio que está dominado también de forma generalizada por los artefactos metálicos.

Sobre estos conjuntos se procedió a una determinación inicial de los restos mediante su identificación anatómica y taxonómica, así como las estimaciones de edad y sexo. Un elemento clave del análisis, especialmente significativo para el estudio de los dados que son objeto de nuestro trabajo, es el estudio de las marcas y alteraciones sobre las superficies de los huesos, hecho que permite distinguir entre evidencias de actuación antrópica y alteraciones biológicas, así como las señales de combustión, que también permiten deducir manifestaciones de carácter tafonómico.

Es el análisis de estos parámetros el que nos permite advertir en ambos yacimientos la existencia de este conjunto singular de dados y elementos auxiliares que es objeto de nuestro estudio. El número de elementos óseos que ofrecen evidencias claras de haber sido manipulados para obtener algún tipo de reutilización no sobrepasa la veintena de ejemplares (1\%) en Mendikute. Se trata de seis tarafes, una ficha decorada, dos cubos sin puntuación y siete ejemplares de preformas o listones.
En el caso de Ausa, los elementos que avalan el proceso de reutilización del hueso son más numerosos, ya que representan la mitad de los ejemplares inventariados, alcanzando el medio centenar de piezas óseas. De este modo, contamos con seis dados o tarafes, cuatro cubos regulares sin puntuación y cuarenta y tres regletas o listones.

\section{RESULTADOS: LOS DADOS DE AUSA Y MENDIKUTE Y SUS PARALELOS}

La naturaleza de los materiales óseos tallados recuperados en Ausa y Mendikute nos permite documentar un proceso local de fabricación de elementos vinculados con el juego, en su mayoría dados (Fig. 3), de cuyo análisis se desprenden dos tipos de informaciones complementarias: por un lado, la existencia de testimonios de las distintas etapas del proceso productivo y, por el otro, los dados ya terminados para su uso. Las evidencias arqueológicas permiten advertir como las diáfisis de los huesos largos han sido labradas hasta conseguir las regletas prismáticas a partir de las cuales se tallan los cubos, desechando las epífisis (Fig. 4) una vez se ha obtenido el listón. Entre el repertorio de elementos auxiliares de esta producción se cuentan también dichos listones, exentos ya de las epífisis óseas, preparados para la obtención de los dados (Fig. 5). Este trabajo sistemático de labra dificulta notablemente tanto la identificación anatómica del hueso como la determinación de su taxonomía, imposible en todos los casos. Es frecuente que estas regletas presenten marcas de talla, muescas o cortes, resultantes de la obtención de los cubos y de los posibles errores de medición cometidos al tallarlos (Fig. 6).

Respecto a los dados terminados, un aspecto especialmente interesante de los mismos, precisamente porque tiene numerosas implicaciones que discutiremos más adelante, es la numeración o disposición de la puntuación. Para ello los distintos ejemplares han sido clasificados de acuerdo con una convención previa (Fig. 7) que intenta arbitrar una descripción homogénea de las piezas para mostrar con mayor claridad tanto los elementos comunes como los aspectos diferenciales que aparecen en los ejemplares. De este modo, ordenamos las caras en torno a la faceta que presenta el valor de seis, situando en la parte superior el valor cuatro y en la parte inferior, siempre que sea posible, el valor tres. A partir de este convenio se desarrollan el resto de las caras, permitiendo la comparación rápida entre los ejemplares estudiados (Fig. 8).

Se advierte que la numeración más habitual de la puntuación responde a la norma de que las caras opuestas de la pieza alcancen un valor de siete; es decir el número 1 figura sobre la cara opuesta del 6, el 2 se opone al 5 y, finalmente, el 3 al 4. Esta disposición se opone a una numeración alternativa probablemente más antigua que distribuye los puntos en una secuencia reglada (1/2, 3/4 y 5/6), donde el uno se opone al 


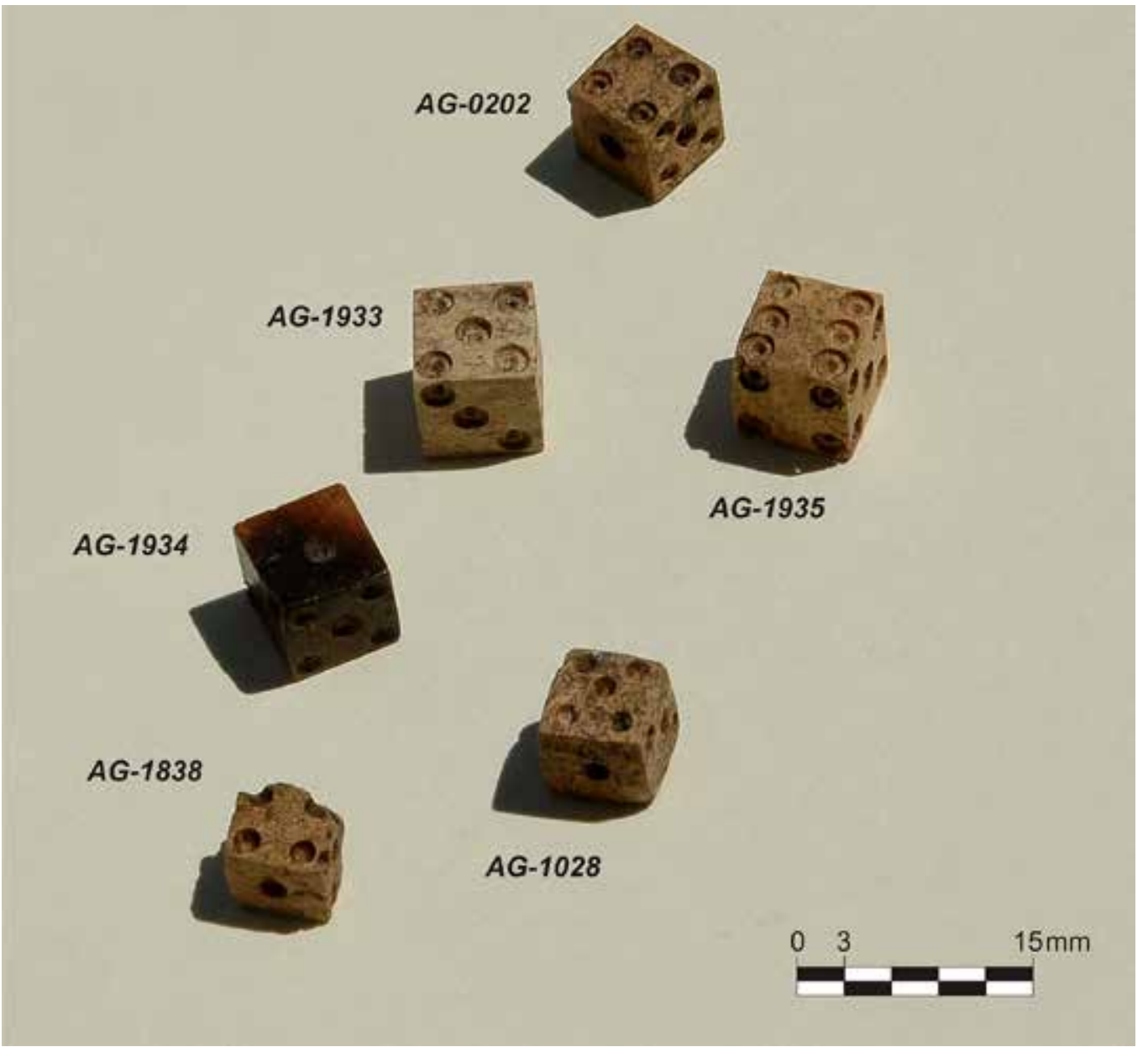

Fig. 3. Conjunto de dados en hueso localizados en el recinto noble de Ausa (Zaldibia, Gipuzkoa). / Assemblage of bone dice found at the noble enclosure of Ausa (Zaldibia, Gipuzkoa).

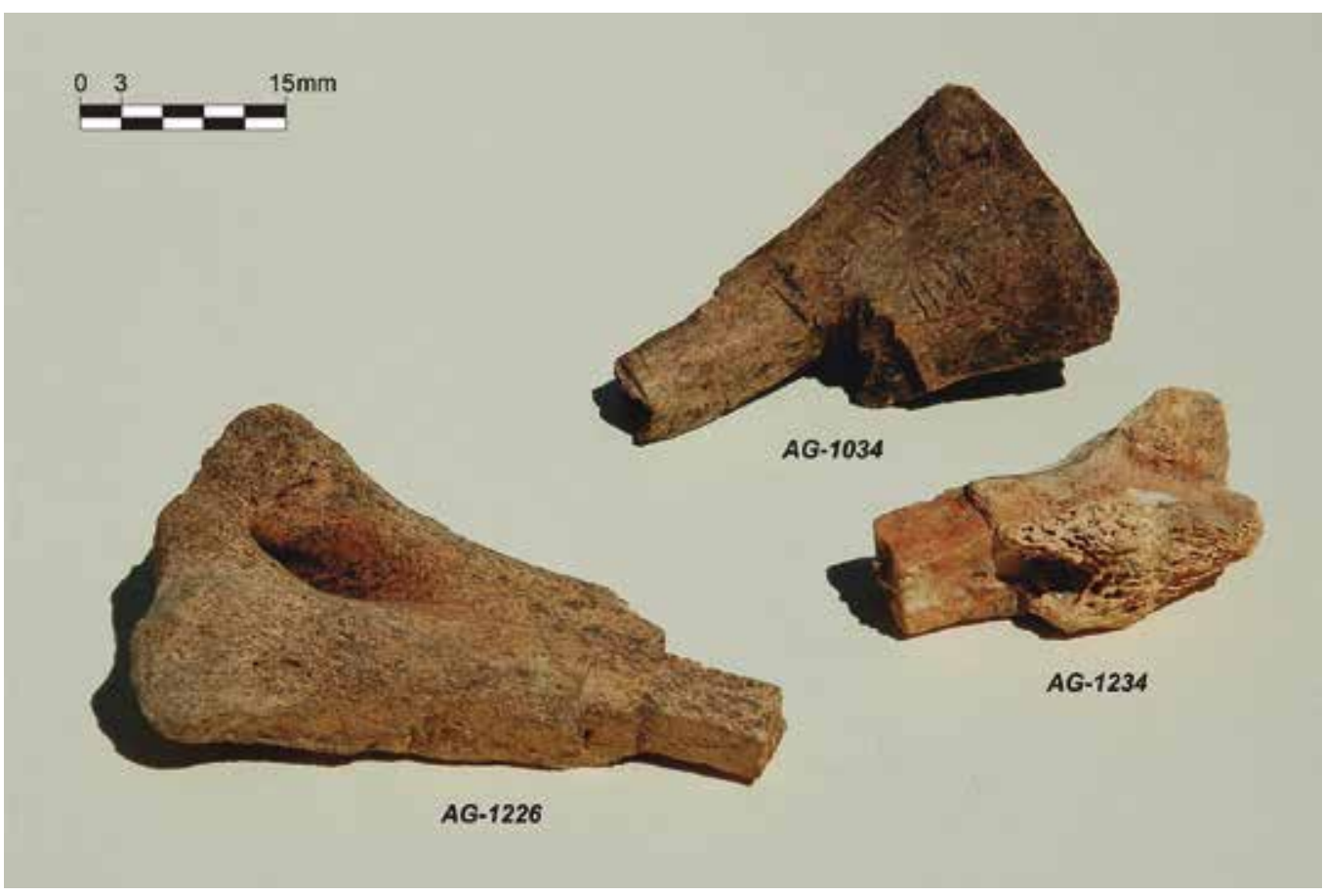

Fig. 4. Epífisis de metápodos con las huellas del trabajo de extracción de las regletas utilizadas en la elaboración de estos elementos lúdicos (Ausa, Zaldibia). / Epiphyses of methapods with marks of extraction of pieces used in the fabrication of dice (Ausa, Zaldibia). 


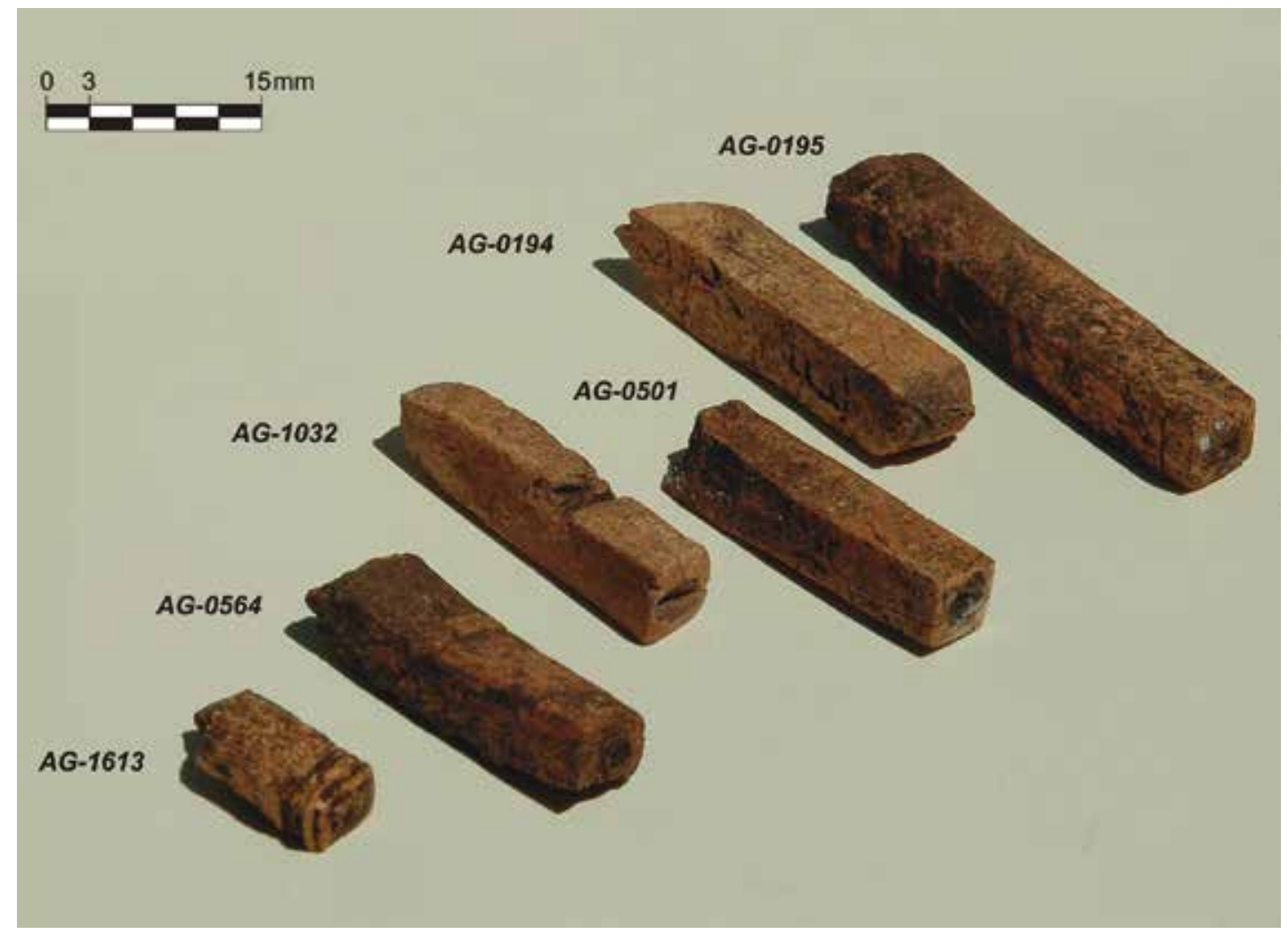

Fig. 5. Grupo de regletas o listones obtenidos a partir de la recuperación de los huesos largos de las especies consumidas en la guarnición (Ausa, Zaldibia). Epiphyses of methapods with marks of extraction of pieces used in the fabrication of dice (Ausa Zaldibia).

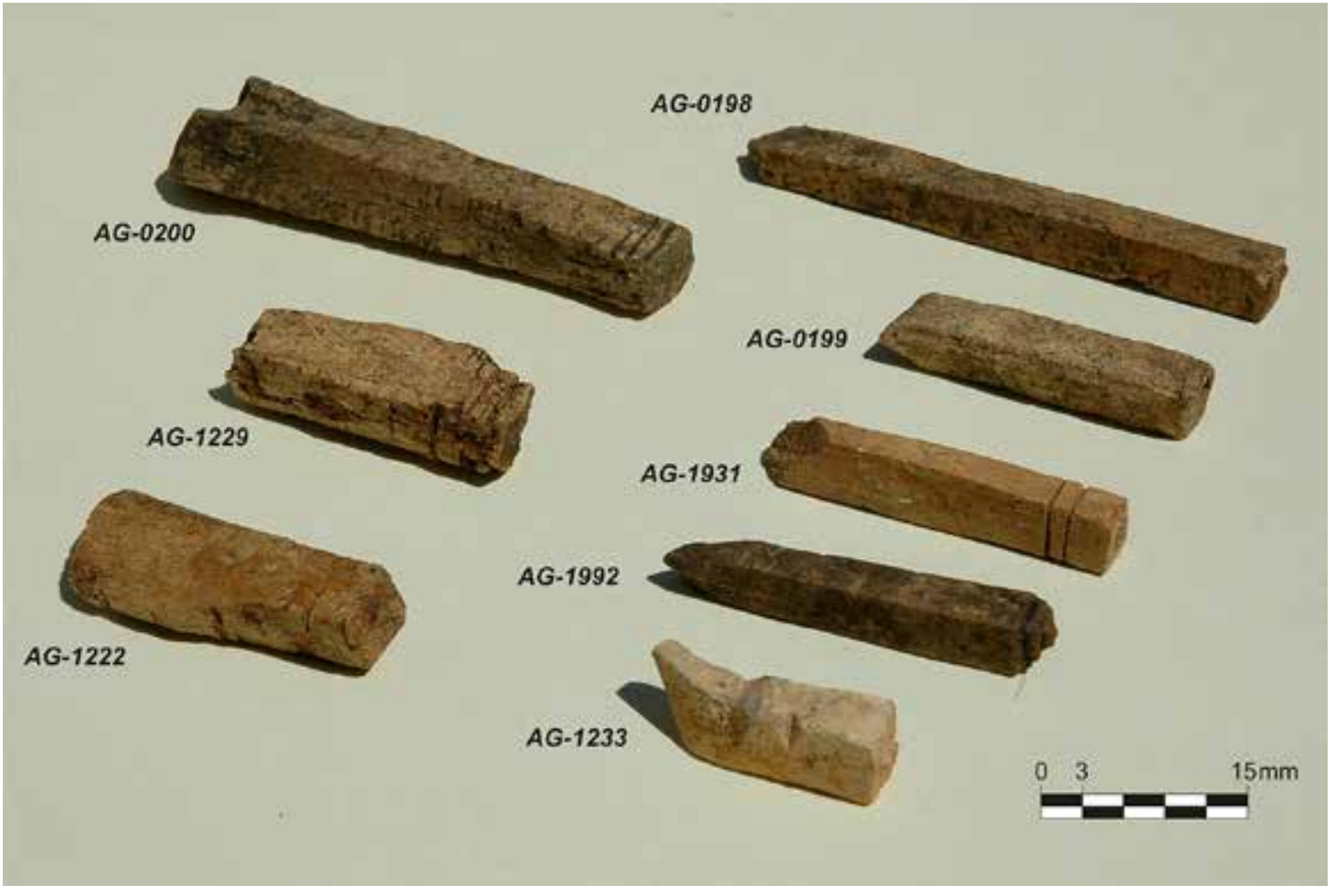

Fig. 6. Preformas 0 regletas en hueso con recortes e incisiones que evidencian algunos de los procedimientos utilizados en la elaboración de estos elementos óseos (Ausa, Zaldibia). / Bone bars with deep cuts or marks revealing the elaboration process of these bone dices (Ausa, Zaldibia). 


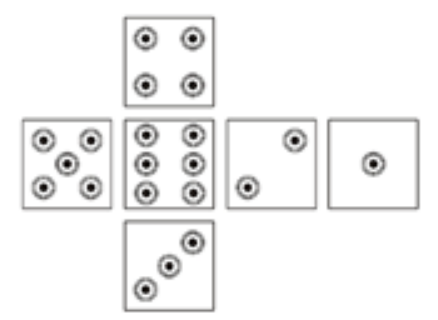

Disposición regular (a) $(1 / 6,2 / 5,3 / 4)$

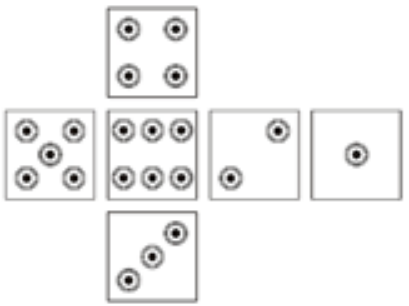

Disposición regular (c)
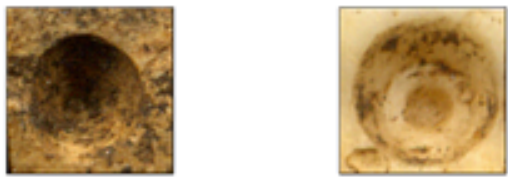

Tipo 1

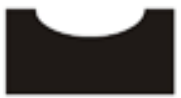

Muesca circular, profunda y sencilla

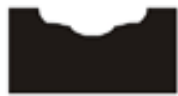
con anillo

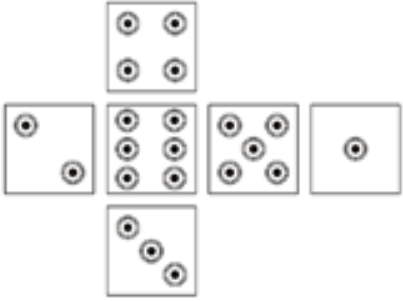

Disposición regular (b)

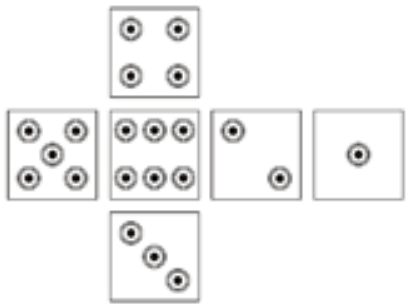

Disposición regular (d)

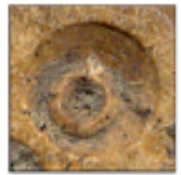

Tipo 3

Muesca profunda rehundido sencillo

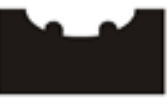

Muesca profunda con anillo rehundido en relieve

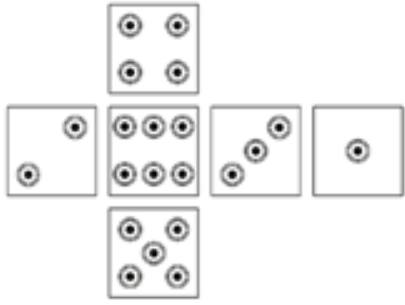

Disposición errática (e) $(1 / 6,2 / 3,4 / 5)$

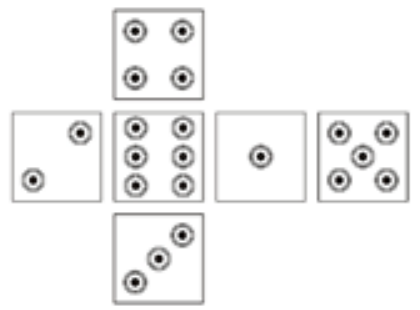

Disposición alternativa $(1 / 2,3 / 4,5 / 6)$

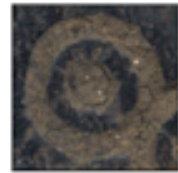

Tipo 4

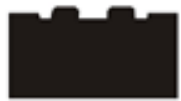

Muesca superficial con anillo y punto que define una arandela en relieve

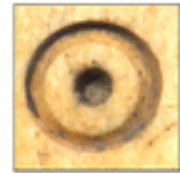

Tipo 5

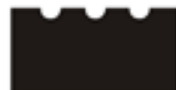

Muescas superficiales con anillo y punto en disposición regular sin relieve

Fig. 7. Cuadro sinóptico de los principales sistemas de numeración de los dados de Ausa y Mendikute (regular, alternativo y errático) con sus variantes, y repertorio de los tipos de puntuación o muescas talladas en las piezas estudiadas. / Summary chart of the main numeration systems of Ausa and Mendikute's dice (regular, alternative and wrong) with their variations, and examples of punctuation types or cuts in the studied pieces. 


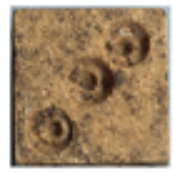

202

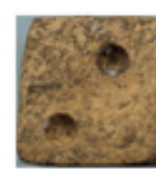

1028

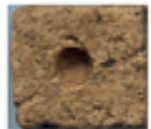

1838

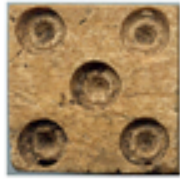

1933

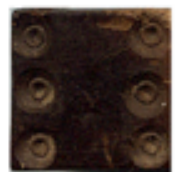

1934

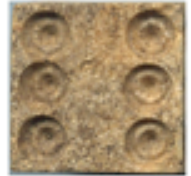

1935

\begin{tabular}{|l|l|l|l|l|l}
\hline Núm. Inv. & Mat. & Numeración & Dimensiones & Puntos & Observaciones \\
\hline AG.- 11.114.202 & Hueso & Regular (a) & $6.9 \times 7 \times 7.1 \mathrm{~mm}$. & Tipo 3 & Bastante regular y de color ocre. \\
\hline AG.- 13.100.1028 & Hueso & Regular (c) & $6.3 \times 6.4 \times 6.6 \mathrm{~mm}$. & Tipo 1 & Talla rudimentaria y caras irregulares. \\
\hline AG.- 12.114.1838 & Hueso & Regular (d) & $5.8 \times 6.1 \times 6.4 \mathrm{~mm}$. & Tipo 1 & Talla rudimentaria y muy deteriorado. \\
\hline AG.- 12.114.1933 & Hueso & Regular (a) & $7.5 \times 7.6 \times 7.7 \mathrm{~mm}$. & Tipo 3 & Regular, buena talla y color ocre. \\
\hline AG.- 12.114.1934 & Hueso & Regular (a) & $7.4 \times 7.7 \times 7.9 \mathrm{~mm}$. & Tipo 3 & $\begin{array}{l}\text { Bastante regular y de color pajizo } \\
\text { (quemado). }\end{array}$ \\
\hline AG.- 12.114.1935 & Hueso & Regular (a) & $7.6 \times 7.7 \times 7.8 \mathrm{~mm}$. & Tipo 3 & Regular, buena talla y color ocre. \\
\hline
\end{tabular}

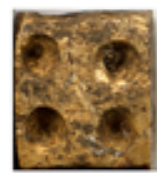

20

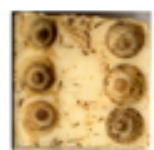

129

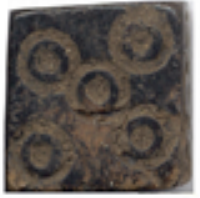

525

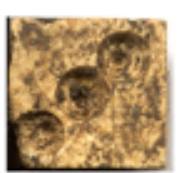

799

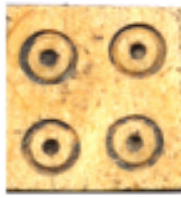

1016

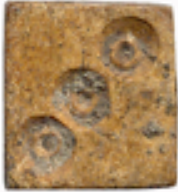

1496

\begin{tabular}{|l|l|l|l|l|l|}
\hline Núm. Inv. & Mat. & Numeración & Dimensiones & Puntos & Observaciones \\
\hline Men.- 11.110.020 & Hueso & Regular (b) & $7.5 \times 6.5 \times 7.5 \mathrm{~mm}$. & Tipo 1 & $\begin{array}{l}\text { Poco regular y de color ocre, } \\
\text { deteriorado. }\end{array}$ \\
\hline Men.- 11.115.129 & Asta & Regular (a) & $6 \times 6 \times 6 \mathrm{~mm}$. & Tipo 2 & $\begin{array}{l}\text { Regular y de buena talla, de color ocre } \\
\text { crema. }\end{array}$ \\
\hline Men.- 10.116.525 & Asta & Errática (e) & $8.5 \times 8.5 \times 8.5 \mathrm{~mm}$. & Tipo 4 & $\begin{array}{l}\text { Bastante regular y de buena talla, } \\
\text { calcinado. }\end{array}$ \\
\hline Men.- 12.160.799 & Hueso & Regular (a) & $7.5 \times 7 \times 7 \mathrm{~mm}$. & Tipo 1 & Regular y de buena talla, de color ocre. \\
\hline Men.- 22.182.1016 & Asta & Regular (a) & $9 \times 8 \times 8.5 \mathrm{~mm}$. & Tipo 5 & $\begin{array}{l}\text { Bastante regular y excelente } \\
\text { conservación. }\end{array}$ \\
\hline Men.- 12.242.1496 & Hueso & Regular (b) & $8.5 \times 8 \times 8 \mathrm{~mm}$. & Tipo 3 & Bastante regular y de color pajizo. \\
\hline
\end{tabular}

Fig. 8. Cuadro-resumen de las características principales de los dados recuperados en las fortificaciones de Mendikute (Albiztur) y Ausa (Zaldibia). Las imágenes se han aumentado al doble de su tamaño./ Summary chart of the main features of dice found at the fortresses of Mendikute (Albiztur) and Ausa (Zaldibia). Pictures are represented twice their size. 
dos, el tres se enfrenta al cuatro y el cinco al seis (Dedies y Sarret, 1981; Collardelle y Verdel, 1993) y que en ningún caso hemos advertido en el conjunto estudiado. Estas características, junto con los contextos estratigráficos tardíos en que fueron recuperados, nos permiten proponer una datación para los dados de Ausa y Mendikute alrededor de los siglos XIII y XIV.

Tanto los ejemplares de Ausa como la mayoría de los de Mendikute respetan esta norma, con la única excepción de la pieza MEN 525, que plantea una distribución errática, ya que mantiene el 1 en la cara contraria al 6 , pero ofrece el 2 opuesto al 3 y el 4 se enfrenta al 5 (1/6, 2/3, 4/5). Respecto a los dados con puntuación presuntamente errática, debemos recordar que existen muchos ejemplos en contextos de cronología muy amplia. Unos responden a una distribución aleatoria de su puntuación como, por ejemplo, la pieza en hueso localizada en las excavaciones de la Vega Baja de Toledo, de factura algo irregular $(8 / 13 \mathrm{~mm})$ y con una puntuación que sigue el orden $1 / 4,2 / 6$ y $3 / 5$, que se atribuye a época tardorromana o altomedieval (Cáceres y De Juan 2010: 329, $n^{\circ} 6$ ). Del mismo modo ocurre con uno de los ejemplares andalusíes del yacimiento de Vascos (Cosín y García, 1998: 46) o con nuestro ejemplar de Mendikute. En estos casos, a pesar de lo errático de la puntuación, no necesariamente deberíamos considerarla como fraudulenta.

Sin embargo, otras veces la posible errata responde a una duplicidad de la puntuación más alta, por lo que no cabe considerarla como un error involuntario. Estos ejemplares falsos o trucados son también muy numerosos, tal es el caso del ejemplar de madera de Colletière, de dimensiones irregulares (18/23 mm.) y con un sistema de numeración tramposo del tipo 1/2, $3 / 5$ y 6/6, que data de principios del siglo XI (Collardelle y Verdel, 1993: fig. 195.15) o de alguno de los ejemplares procedentes del Petit Palais de Avignon, que mencionábamos más arriba.

Entre el conjunto de dados con numeración correcta, la distribución regular de la puntuación sobre las caras del dado presenta, además, algunas pequeñas modificaciones, menos importantes, como podemos advertir en estos ejemplares. El modelo más representado en ambos yacimientos ofrece los valores 1, 2 y 3 en torno a un mismo vértice del dado, ordenados en sentido inverso a las agujas del reloj (disposición a). Nueve piezas siguen esta distribución, frente a dos ejemplares de Mendikute que reúnen en un mismo vértice aquellos valores, pero dispuestos en sentido contrario (disposición b).

Por otra parte, no existe uniformidad a la hora de disponer los puntos sobre la cara que representa el 6 , ya que por referencia a las caras contiguas tanto aparecen en vertical como en horizontal. Del mismo modo, ocurre con la disposición en diagonal que plantean la cara 2 y 3 , ya que encontramos ejemplos tanto de derecha a izquierda como a la inversa (disposiciones c y d). Sin embargo, cabe tener en cuenta que estas va- riaciones son poco significativas, por cuanto no modifican sustancialmente la distribución de la puntuación. En ningún caso, pues, se advierte la existencia de la puntuación alternativa, presuntamente anterior al siglo $\mathrm{XIII}$, en los yacimientos de Ausa y Mendikute.

En lo relativo a la forma de tallar los puntos, puede observarse como existe una cierta homogeneidad morfológica en los tarafes de Ausa ya que la muesca profunda con un anillo rehundido y en relieve es el tipo de talla preferente para los dados con disposición regular. A ello se une el hecho de que todos ellos presentan dimensiones bastante regulares, con pequeñas variaciones, pero en torno a los $7.5 \mathrm{~mm}$. Solamente dos ejemplares de todo el conjunto -los mismos en los que se advertían algunas variantes leves en la disposición de los puntos- presentan muescas circulares, profundas y sencillas que configuran un único punto rehundido sin mayores ornamentaciones, de talla algo rudimentaria y con peor acabado que el conjunto mayoritario. Los dados de Mendikute, en cambio, presentan una heterogeneidad mayor en su conjunto. De tamaños algo más dispares, con una horquilla de dimensiones comprendida entre los 6 y $9 \mathrm{~mm}$, no resulta posible asignar un tipo de muesca a una distribución de la numeración en concreto y no parece haber preferencias respecto de los tipos de talla.

La presencia de regletas, listones o cubos tallados sin numerar atestiguan la producción in situ de estos elementos lúdicos, producción que no parece ser exclusiva de los yacimientos de Ausa y Mendikute. Sin ir más lejos, los trabajos arqueológicos realizados entre 2001-2002 en la vecina fortificación fronteriza de Gorriti no consiguieron recuperar allí ningún dado completo, pero documentaron numerosos fragmentos de hueso trabajados destinados a la consecución de regletas para la elaboración posterior de fichas y dados. Las ilustraciones, que acompañan el breve comentario sobre estos materiales, muestran que también en aquella guarnición navarra se elaboraban como en las fortificaciones precedentes pequeños objetos lúdicos a partir de restos óseos, confirmando las imágenes que acompañan al texto las distintas etapas de elaboración (Ramos Agirre, 1984: 60).

El hallazgo de dados, fichas de juego y los materiales diversos que pueden relacionarse con su proceso de fabricación en la sierra de Aralar no constituye en absoluto un fenómeno aislado dentro del panorama de la arqueología medieval en Europa. Ciertos trabajos de construcción en el centro urbano de Montpellier (Hérault, Languedoc-Roussillon) darían lugar al descubrimiento, en 1985, de un profundo pozo amortizado por sedimentos arcillosos y un número ingente de objetos y residuos medievales. Las particulares condiciones del hallazgo habían contribuido a la conservación de un conjunto mueble excepcional que muestra una imagen cercana de la vida cotidiana de esta villa mediterránea a lo largo del siglo XIII. Entre otros materiales destacan tanto por su número como su diversidad un conjunto 
extraordinario de más de medio centenar de piezas de vajilla de madera, así como otras tantas decenas de objetos en madera, que sólo conocíamos a través de los ejemplares ejecutados en materiales más nobles.

Platos y escudillas, pero también cucharas, cuchillos, peines, juguetes y piezas de ajedrez, que han sido probablemente importados desde distintos lugares del Mediterráneo, forman parte de este singular hallazgo, que ha sido expuesto en distintos eventos (Viure a Palau, 2004: 254-257). El conjunto aportó, además, veintiséis dados elaborados en hueso, que responden a distintos módulos (6, 8 y $9 \mathrm{~mm}$ de lado), dándose la circunstancia de que ocho ejemplares carecían de puntuación. La presencia de estas piezas inacabadas permite sugerir a la autora que pudo estar cercano su lugar de elaboración (Leenhardt, 1999: 172-3).

Las excavaciones en la fortificación de Montségur (Ariège, Midi-Pyrénées) proporcionaron un conjunto de diez dados, recuperados en su mayoría en las construcciones aldeanas que se encuentran al pie del torreón rectangular que preside el recinto fortificado. Las piezas presentan, también aquí, dimensiones variables, que abarcan de los 6 a los $9 \mathrm{~mm}$ de lado, y fueron talladas en hueso (7), marfil (2) y esteatita (1). Son, en su mayoría, algo irregulares, ya que únicamente uno de los ejemplares puede considerarse claramente cúbico. La descripción meticulosa de estas piezas permite saber que seis de los ejemplares mantienen una disposición regular de su puntuación conforme a la norma de que la suma del valor de las caras opuestas es siete, mientras mantienen el orden inverso en la distribución sobre el mismo vértice de los valores uno, dos y tres (Dedies y Sarret, 1981: 218). De forma que esta muestra, que fecha en la primera mitad del siglo XIII, viene a ratificar que todavía coexisten piezas con una distribución dispar de su numeración, a pesar de las referencias documentales a favor de que el marcado de los dados se ajustara a ciertas características comunes.

Más al Oeste, en tierras de Gascuña, los trabajos en el castillo de Corné en L'Isle-Bouzon (Gers, Midi-Pyrénées) recuperaron junto a algunos elementos musicales, como un birimbao, varios silbatos en hueso y un cordal de viola, un pequeño número de objetos lúdicos entre los que se encuentran cuatro dados. En este caso, el tamaño de estas piezas en hueso se circunscribe a las medidas conocidas, tres ejemplares son reducidos $(7,5 \mathrm{~mm}$ de lado) y el cuarto es algo más voluminoso $(8,9 / 9,5 \mathrm{~mm})$, ofreciendo una disposición regular de su puntuación con valor de siete para sus caras opuestas. De todas formas, su talla es imperfecta, por lo que no llegan a constituir una forma plenamente cúbica. Esas deficiencias se hacen palpables al observar la colocación de la puntuación, que está constituida por dos círculos concéntricos entorno a un punto central (Lasure, 1998: 440-1). Sin embargo, estas imperfecciones no fueron obstáculo para que estas piezas fueran utilizadas normalmente en el juego como parece advertirse ante el desgaste de sus aristas.
Existen otros muchos hallazgos en la región, que pudieron contemplarse con motivo de una amplia exposición sobre Arqueología y vida cotidiana de los siglos XIII y XIV celebrada en Toulouse. En aquella ocasión, se expusieron, además, de algunos de los ejemplares de Montségur (Archéologie et vie quotidienne, 1990: $\mathrm{n}^{\circ}$ 344-6), un ejemplar procedente de Toulouse y otro del yacimiento de Orgueil en Mauroux (Lot) (Archéologie et vie quotidienne, 1990: $n^{\circ}$ 347-8). De todos modos, uno de los aspectos más interesantes recogidos en esta exposición corresponde al hallazgo en el mismo centro urbano de Toulouse (place des Carmes) de los vestigios de un área de elaboración de objetos óseos, que debe datarse en la primera mitad del XIII (Archéologie et vie quotidienne, 1990: 294-5). Las piezas expuestas mostraban que los dados formaban parte de los objetos elaborados en el área artesanal, mediante un proceso muy similar a las etapas de manipulación del material óseo que advertíamos en el caso de las fortificaciones guipuzcoanas.

Cabe destacar, además, un importante conjunto de piezas recuperadas en las excavaciones del Petit Palais de Avignon que se encuentran actualmente en proceso de estudio. Tres de los ejemplares que componen esta muestra serían seleccionados para una conocida exposición sobre la vida cotidiana a través de la arqueología que recorrió el Mediodía francés. Los tres dados expuestos, elaborados en hueso, presentaban distintos tamaños $(7,11$ y $6 \mathrm{~mm}$. de lado, respectivamente). El segundo ejemplar tenía la particularidad de mostrar parcialmente obliterados sus puntos con algún tipo de pasta negruzca, mientras el tercero ofrecía los mismos números pares en dos de sus caras, por lo que debemos suponer que se trataba de un dado trucado.

\section{DISCUSIÓN: LOS PROCESOS DE ELABORA- CIÓN DE DADOS Y SU CRONOLOGÍA}

El conjunto de elementos recuperados en las fortalezas de Ausa Gaztelu y Mendikute, tanto los dados como el conjunto de elementos complementarios que atestiguan su fabricación en dichos enclaves, avalan el proceso de elaboración de estos objetos lúdicos que conocemos a partir de las representaciones iconográficas de la época y de los restos arqueológicos y documentales, por lo que disponemos de elementos para trazar una descripción del proceso de manufactura de dados bastante ajustado a la realidad en base a las materias primas utilizadas, la talla de los cubos, la disposición de la puntuación y su marcado.

\subsection{Las materias primas}

En la elaboración de dados y fichas de juego se utilizaron materiales muy diversos como la madera, el hueso y el marfil, pero también se tallaron tanto en rocas (como la esteatita o el mármol) como en piedras semipreciosas (ámbar, ágata o lapislázuli), conociéndose 
ejemplares en terracota e incluso en bronce (Cosín y García, 1998: 45; Chandevau, 2002: 67). Sin embargo, el material por excelencia utilizado en la manufactura de estos objetos lúdicos fue tradicionalmente el material óseo.

Estos elementos propios de los juegos de azar, que se conocen desde la más remota antigüedad, han adoptado a lo largo del tiempo formas y tamaños muy diversos. Baste recordar como en época romana, los ejemplares cúbicos en hueso, que suelen ser los más habituales (Catálogo MNAR), conviven con piezas fabricadas en otros materiales o presentan también otras formas poliédricas (Cosín y García, 1998). De todos modos, la descripción isidoriana ("Tesserae vocatae quia quadrae sunt ex omnibus partibus" Etymologiarum, XVIII, 63) reserva el uso del término para los ejemplares cúbicos que son, en definitiva, los que han venido predominado en Occidente hasta nuestros días.

Estos objetos, así como las fichas o peones que los acompañaban, continuaron siendo elaborados preferentemente en hueso a lo largo de época medieval, a pesar del empleo circunstancial de otros materiales alternativos, como la madera o la esteatita. La preferencia por este material queda confirmada también por el texto alfonsí ( "E estos dados pueden ser fechos de fuste o de piedra o de huesso o de todo metal, mas señaladamientre, son mejores de huesso, el más pesado que fallaren, que d'otra cosa ninguna, e más igualmientre e más llanos caen doquier que los echen" - Libro de los juegos 2007, 255-), aunque las razones para aquella predilección tampoco resultan demasiado claras. Sea como fuere, los dados tallados en hueso corrieron por las tablas y mesas de juego de los más diversos escenarios y estamentos sociales de época medieval, como podremos comprobar más adelante. No en vano este constituye el material prioritario utilizado en las fortalezas que nos ocupan (Fig. 9)

\subsection{El proceso de elaboración}

El Libro de los juegos de Alfonso X ofrece también algunas referencias que nos ilustran sobre el proceso de elaboración de estas piezas cúbicas. Una de las miniaturas que orna el principal manuscrito alfonsí (Escorial, T.I.6, fol. 65 v.) nos relata gráficamente las principales operaciones que se siguen en la manufactura de estas piezas. La imagen, que ha sido reproducida en diversas ediciones y estudios realizados sobre esta obra (Libro de los juegos 1987, 2007), es bien conocida $\mathrm{y}$, aunque no parece necesario volverla a reproducir, es digna de ser comentada (Musser, 2007).

La ilustración, que encabeza la sección correspondiente al Libro del juego de los dados, ha sido resuelta con frescura y originalidad. En una misma composición y a través de siete personajes, el miniaturista describe las principales etapas de elaboración de estas piezas de hueso. Un grupo de tres artesanos, sentados sobre su correspondiente banco de trabajo, nos muestran las operaciones básicas para obtener los cubos o futuros dados. El primero, dedicado a la obtención del material en bruto, elimina con un cuchillo o machete las partes inservibles del hueso, mientras en el suelo se acumulan junto a un recipiente los residuos que genera esta operación. Junto a él, un segundo operario se dispone a cortar longitudinalmente la caña del hueso largo, que apoya sobre la mesa de trabajo, a fin de obtener las regletas o listones prismáticos. El tercer operario, por su parte, procede a cortar las regletas con una sierra de arco a fin de obtener las piezas cúbicas. Los futuros dados caen en un pequeño saco que pende de la mesa de trabajo, mientras en el suelo aparecen apilados en un vaso otros tantos listones (Menéndez-Pidal, 1984: Lám. VIII, fig. 20).

El segundo grupo de operarios, que aparecen en una disposición diferente a los precedentes, nos presentan la etapa final de elaboración. Uno de los artesanos se dedica a igualar las caras del cubo, para lo cual frota el futuro dado sobre una probable piedra de grano fino a fin de regularizar y pulir su superficie. Una jarrita y una escudilla con algún tipo de polvo aparecen sobre la mesa, aludiendo, tal vez, al agua y al abrasivo utilizado en el pulimento de la pieza. Un segundo operario procede a marcar con ayuda de un parahuso o taladro manual la puntuación en las facetas del dado, mientras los ejemplares terminados se alinean sobre la mesa (Menéndez-Pidal 1984, Lám. VIII, fig. 21). Finalmente, el relato gráfico parece aludir alegóricamente en su última escena al destino de estas piezas, a partir de un personaje femenino que muestra varios dados a un probable tahúr.

Por otra parte, las herramientas y útiles que aparecen representados en esta miniatura de finales del siglo XIII son prácticamente idénticos a los que siglos después seguían utilizándose en esta manufactura. Una de las planchas, que dedica L'Encyclopédie de Diderot y D'Alembert al artesanado de la época, evoca un taller de elaboración de perlas y cuentas de rosario (Recueil de planches VIII, Patenôtrier). Los objetos descritos en este espacio artesanal nos inducen a pensar que buena parte del instrumental y los procedimientos de base aplicados en el siglo XVIII seguían fieles a una larga tradición artesanal. Las innovaciones introducidas en el oficio no habían conseguido arrinconar los cuchillos tradicionales o la sierra de arco, ni tampoco los procedimientos de obtención de los listones prismáticos en hueso. Por todo ello, la presencia en Ausa y Mendikute de estos elementos prismáticos que atestiguan el proceso de fabricación de los dados, constituye una prueba evidente de esta producción local.

\subsection{La disposición de la puntuación}

Como es sabido, los dados o tarafes son piezas cúbicas que ofrecen en sus respectivas caras una numeración en puntos que va del uno al seis, por lo que en conjunto la puntuación de cada ejemplar alcanza un valor de veintiún puntos. Sin embargo, la disposición 


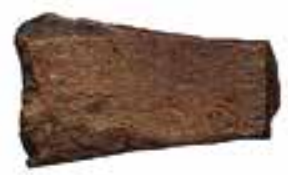

1.

Men.-1414

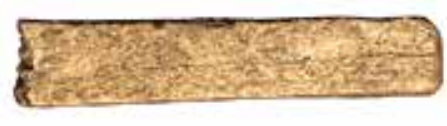

2.

Men.-198

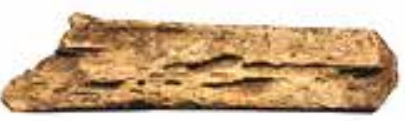

3.

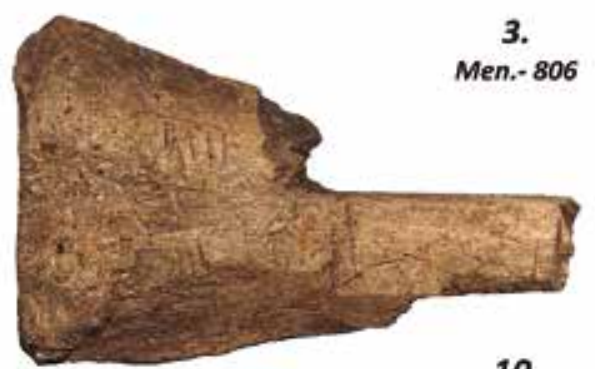

10.

AG.-1034

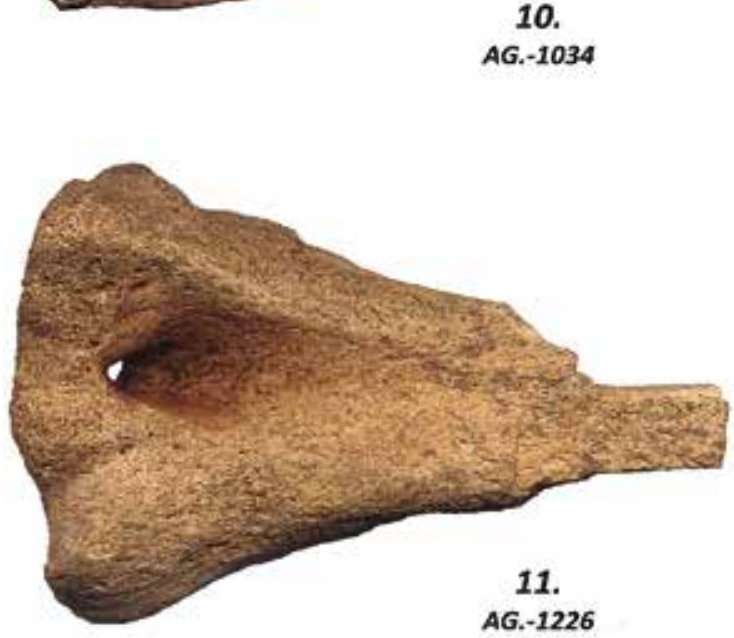

AG.-1226

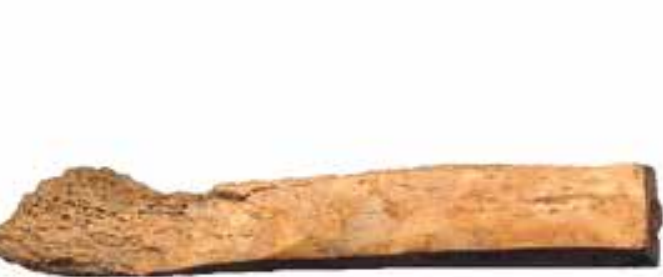

16.

03

$15 \mathrm{~mm}$
5.

Men.-217

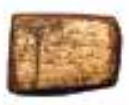

4.

Men.-1126
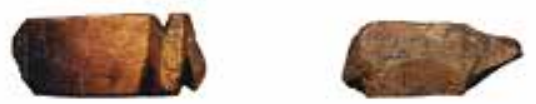

6.

Men.- 826

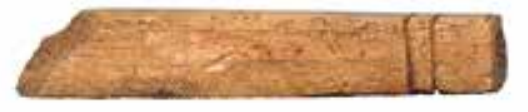

12.

AG.-1931

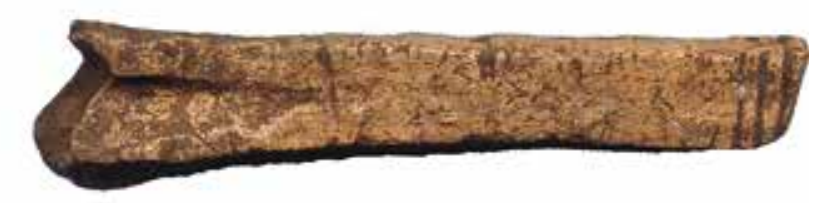

14.

AG.-200

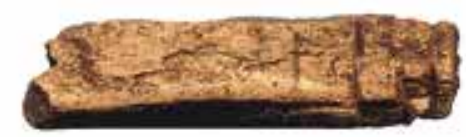

15.

18.

AG.-1229

AG.-1029

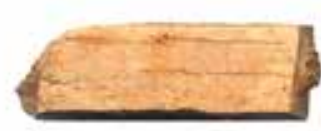

17.

AG.-1233
7.

Men.-800

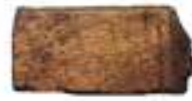

13.

AG.-201

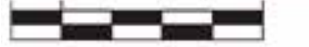

Fig.9. Selección de residuos y desechos de la manipulación del material óseo, que testimonian la elaboración local de los objetos lúdicos precedentes. Las piezas núm. 1 a 9 proceden de Mendikute, mientras los objetos del 10 a 20 fueron recuperados en las excavaciones del recinto noble de Ausa. Entre estos elementos, que se presentan a tamaño natural, destacan dos cubos sin muescas (7 y 20) y, en particular, una probable ficha o peón (9), ya que es la única pieza de estas características con la que contamos. / Selection of residues and remains of manipulated bones that evidence the local production of dice. Individuals 1 and 9 come from Mendikute, while individuals 10 to 20 were found at the noble enclosure of Ausa. Among these elements, represented at their natural size, there are a couple of cubes without points (7 and 20) and a game piece (9), which is the only piece of these features. 
u orden de la puntuación sobre las caras del dado no siempre se ha ajustado a una misma norma, como podemos comprobar a través de los ejemplares medievales recuperados en numerosas intervenciones arqueológicas europeas.

Esta discordancia ha sido interpretada con frecuencia como un indicio cronológico relativo, ya que ciertos ejemplares altomedievales demostrarían la vigencia de una norma antigua que habría acabado cediendo ante el proceso de normalización de la puntuación que consignan definitivamente los textos (Mehl, 1990: 81). Desde esta posición, el sistema de numeración anterior al siglo XIII conforme al uso antiguo ofrecería una distribución reglada (1/2, 3/4 y 5/6), donde el uno se opone al dos, el tres se enfrenta al cuatro y el cinco al seis (Dedies y Sarret, 1981; Collardelle y Verdel, 1993).

Sin embargo, aquella disposición antigua, que no siempre fue respetada sistemáticamente, habría quedado en desuso en el transcurso del siglo XIII, pasando la numeración habitual de los dados en Occidente a ajustarse a una regla fija en la que la suma de los puntos de las caras opuestas debía ser igual a siete $(1 / 6,2 / 5,3 / 4)$, conforme al modelo que ya era utilizado en el mundo romano (Mac Gregor 1985, 129-132) y que documentamos ampliamente en los yacimientos analizados. De esta forma, los ejemplares posteriores que presentaban un sistema de numeración alternativo pasaban a considerarse irregulares, como exponentes residuales de unos usos que habrían sido arrinconados definitivamente en la plenitud medieval.

Sin embargo, esta propuesta secuencial que defiende el predominio de una norma determinada de la puntuación según el periodo cronológico entra en contradicción con un número cada vez mayor de evidencias arqueológicas que vienen a confirmar que ambas normativas coexistieron en paralelo a lo largo del Medievo. A pesar de que no contamos con una justificación clara de esa alternancia, cabe advertir que el sistema clásico de numeración, que todavía hoy utilizamos, fue preponderante sobre todo en la Europa Meridional, mientras que el modelo alternativo parece haber sido utilizado con mayor asiduidad en algunas regiones del Norte de Europa (Brown, 1990: 692). De todas formas, esta generalización es meramente indicativa, ya que son numerosas las excepciones tanto en uno como en otro caso, constatándose con relativa frecuencia el uso paralelo de ambos sistemas.

El yacimiento lacustre de Paladru (Isère, Bas-Dauphiné), por ejemplo, ha proporcionado una muestra nada desdeñable de objetos lúdicos (piezas de ajedrez, fichas y dados) labrados en madera que datan de la primera mitad del siglo XI. Los dados, que aparecen en este repertorio, corresponden con tres cubos irregulares en madera de fresno y muestran en sus caras la numeración pirograbada. Los dos primeros ejemplares están numerados conforme al sistema alternativo (1/2, $3 / 4,5 / 6)$, mientras el tercero repite en dos de sus caras el valor de seis. (Collardelle y Verdel, 1993: fig. 195,
13 y 14). No se trata de un caso extraño, ya que se ofrece como paralelo un ejemplar en hueso con la misma numeración, fechado en el siglo $X$, procedente del emplazamiento fortificado de Verger en Saint-Romain (Côte-d'Or).

Por otra parte, las excavaciones de Martin Briddle en Winchester aportan un buen contrapunto sobre esta cuestión. El estudio de una veintena de ejemplares, que provienen de una larga secuencia que abarca desde contextos altoimperiales hasta niveles del siglo XVIII, ofrece algunas precisiones significativas. En este caso, algo más de la mitad de los ejemplares presentan una numeración clásica (13), al estilo de la utilizada en la actualidad, frente a un número similar (10) que se ciñe al sistema alternativo (1/2,3/4, 5/6). Sin embargo, la distribución de estos testimonios conforme a su probable cronología indica que las piezas con numeración clásica se registran, salvo en la etapa anglosajona, a lo largo de todos los periodos. Por el contrario, los ejemplares con numeración alternativa se concentran íntegramente dentro del periodo comprendido entre el siglo XIII y el XVI (Brown, 1990: t. 83). Los testimonios parecen corroborar en este caso la utilización en paralelo de ambos sistemas a lo largo del periodo bajomedieval, precisamente en el momento en que las ordinaciones y tratados abogaban de forma unánime por una misma numeración.

El texto alfonsí, por ejemplo, puntualizará de forma clara en esta materia ("E deven ser puestos los puntos en esta guisa: so la faz del seis el as, e so el cinco el dos, e so el cuatro el tría." Libro de los juegos 2007, 256). En el mismo sentido, se expresan los estatutos de los fabricantes de dados (deciers) de la villa occitana de Toulouse en 1297 al precisar en su articulado que los puntos de las caras opuestas deben ser siempre iguales a siete ("non sit ausus facere taxillos seu daezs nisi septennos inter partem superiorem et inferiorem, videlicet de VI punctis in una parte et in alia inferiori de uno puncto ..." Fagniez 1898, I, 321). Sin embargo, estas normativas que aspiraban a adoptar un sistema único en la disposición de la puntuación, al objeto de reducir en lo posible los dados trucados y el uso de piezas fraudulentas, estaban todavía lejos aplicarse de forma generalizada, especialmente si se trataba de piezas de fabricación casera o local, como es nuestro caso. Cabe recordar, además, que existe un apego particular entre el jugador y sus propios dados, aspecto que convierte a estos instrumentos del azar en objetos de carácter estrictamente personal (Mehl, 1990: 79).

\subsection{El marcado de las muescas y su relleno}

Se insiste con frecuencia en la idea de que el aspecto general de los puntos de los ejemplares medievales suele diferir de las piezas de época clásica (Mehl, 1990: 81), aunque estas diferencias no siempre resultan tan evidentes como se pretende. Los dados romanos, por lo general algo más voluminosos, ofrecen alguna 
preferencia por una puntuación formada a partir de un punto central rodeado por dos círculos concéntricos, aunque no se descarta el uso de otros estilos (Catálogo MNAR). Por su parte, los ejemplares medievales, de formato más reducido, son marcados a mayor profundidad, preferentemente, con un solo punto y anillo (Fig. 6). Ambos elementos, que aparecen con frecuencia integrados en las piezas medievales, se alternan con la utilización de la muesca cónica simple, aunque este estilo de puntuación no acabará por generalizarse de forma extensiva hasta época moderna.

Con frecuencia, las muescas o puntos de algunos dados fueron rellenados con algún tipo de pasta adherente, a fin de conseguir elevar el contraste de los valores sobre el soporte. En unos casos, se menciona la utilización de pastas negras, como por ejemplo, las trazas que ofrece el dado islámico de Albox (Espinar y Domínguez, 1987), los ejemplares de Montségur (Dedies y Sarret, 1981) o ciertas piezas del Petit Palais de Avignon (Aujourd'hui le Moyen Âge, 1981); En otros, por el contrario, se exige que los puntos sean blancos, como ocurre en los estatutos de Toulouse de 1297 (Mehl, 1990: 81), tal vez porque se alcanza el mismo contraste, oscureciendo y lustrando al fuego el cuerpo del dado conforme a algunas técnicas de acabado que ya habían sido utilizadas desde antiguo. Sin embargo, contamos con escasas referencias respecto a la composición del material utilizado en el rellenado de las muescas. Por ello, resulta interesante constatar que entre las piezas recuperadas en Winchester existen dos ejemplares de factura artesanal, de probable origen medieval, que presentan en su puntuación incrustaciones de estaño (Brown, 1990: 693).

\section{CONCLUSIONES}

El conjunto recuperado permite corroborar la producción local de estos elementos lúdicos a partir de los numerosos restos de talla que se advierten en el conjunto de material faunístico de ambos yacimientos, entre el que se cuentan regletas, listones, pequeñas piezas cúbicas ya preparadas para grabar la puntuación, entre los elementos más comunes que permiten reconstruir dichas actividades, así como una ficha o peón que avala la fabricación de otros objectos lúdicos aunque no contemos con más ejemplares (Fig. 9). El recurso a la inconografía y la documentación escrita aportan elementos suficientes para interpretar este conjunto de materiales arqueológicos y su cronología, para la cual puede establecerse una horquilla que abarca los siglos XIII y XIV.

El recurso a los materiales óseos para la elaboración de toda suerte de utensilios y elementos muebles en un contexto cotidiano es harto frecuente a lo largo de la Edad Media. Basten como ejemplo las arquetas construidas en asta y hueso halladas en un contexto islámico como la arqueta tallada del castillo alicantino de la Torre Grossa (Jijona) (Azuar, 1997). La dureza de estos materiales, especialmente de las astas de cérvidos, los hace espacialmente aptos para la talla de objetos altamente duraderos (López Padilla, 2010). Los elementos lúdicos, preferentemente dados tallados en este material son habituales, tal como hemos tenido ocasión de comentar en este trabajo y existen paralelos europeos y peninsulares tanto tallados en hueso como en otros materiales (Zozaya, 1995).

Los rasgos de estos tarafes, heterogéneos, con disparidades en la disposición de la puntuación, e irregularidades varias sugieren una producción sencilla, destinada al uso personal y colectivo de los ocupantes más inmediatos de estas fortalezas, probablemente sin mayores pretensiones de exportación o abastecimiento a ningún otro núcleo cercano, obviamente, porque tampoco la legislación lo permite, ya que el juego y las actividades que con él se relacionan están controladas fiscalmente por la corona mediante el sistema de las tahurerías (Domínguez y Munarriz, 1993: 604). En cualquier caso, esta pequeña colección de materiales en hueso constituye una buena muestra del arraigo que esta actividad lúdica tiene entre la población que se mantiene, en ocasiones de manera clandestina a pesar de las ordenanzas reales y municipales (Molina, 1999: 99).

No en vano, la presencia de un ejemplar errático aunque no fraudulento- permite intuir la moral laxa de sus fabricantes ante una actividad bien pautada y regulada desde el poder con el fin de minimizar los altercados potenciales derivados de las actividades relacionadas con el juego que van más allá del mero comportamiento lúdico mediante apuestas frecuentes que pudieron ser origen de no pocas alteraciones del orden público. Probablemente los dados de Ausa y Mendikute junto con todos sus desechos de producción no constituyeron más que un mero ejercicio de distracción al margen de las regulaciones propias de los ambientes urbanos.

\section{AGRADECIMIENTOS}

El trabajo presentado se cuenta entre las tareas habituales del Grupo de Investigación en Arqueología Medieval y Post-Medieval de la Universidad de BarceIona (GRAMP.UB), reconocido y consolidado por la Generalitat de Catalunya (2017SGR-833-GRC). Las excavaciones de Ausa Gaztelu y Mendikute fueron posibles gracias a la realización de un proyecto titulado "Reorganización del espacio y estructura de poblamiento en la cuenca alta del río Oria (s. XI-XII, Gipuzkoa)", dirigido por el Dr. J. I. Padilla y financiado por la Diputación Foral de Gipuzkoa y el Gobierno Vasco.

\section{BIBLIOGRAFÍA}

Alfonso X el Sabio, 1987. Libro de ajedrez, dados y tablas. Vicent García Editores, Valencia \& Ediciones Poniente. Vol. I: Estudios introductorios y transcripción; Vol. II: Edición facsimilar. Madrid. 
Alfonso X el Sabio, 1987. Libro de los juegos: Acedrex, Dados e Tablas. Ed. R. Orellana Calderon. Fundación José Antonio de Castro. Madrid.

Archéologie et vie quotidienne aux XIIle-XIVe siècles en Midi-Pyrénées. Catalogue d'exposition, Musée des Augustins (7 mars - 31 mai 1990), 1990. Toulouse.

Aujourd'hui le Moyen Age. Archéologie et vie quotidienne. Catalogue d'exposition (G. Démians d'Archimbaud, Y. Esquieu, D. Foy et L. Vallauri, edits.), Abbaye de Sénanque (juin - septiembre 1981), 1981. Marseille.

Azuar, R., López Padilla, J.A., 1997. Arquetas andalusíes de hueso y asta de ciervo (s. XII-XIII). El taller del Castillo de la Torre Grossa de Xixona (Alicante). Arqueologia Medieval 5, 163-176.

Brown, D., 1990. Dice, a games-board, and playing pieces. In: Object and Economy in Medieval Winchester (General Editor, M. Biddle), 692-706. Winchester Studies 7.ii. Artefacts from Medieval Winchester. Clarendon Press, Oxford University Press, New York.

Cáceres, Y., De Juan, J., 2010. El material óseo trabajado del yacimiento arqueológico de la Vega Baja (Toledo). In: García, A., Izquierdo, R., Olmo, L., Peris, D. (Eds.), Espacios urbanos en el Occidente Mediterráneo (s. VI-VIII). Toletvm Visigodo. Ciudad Real.

Catálogo digital del Museo Nacional de Arte Romano. Available from: http://museoarteromano.mcu.es/acceso_catalogo. html [consulta: 10/07/12].

Chandevau, F., 2002. La motte castrale de Boves (Somme). Tabletterie et petits artefacts (Xe-XVle siècles). Revue archéologique de Picardie 1/2, 25-71. Available from : http:// www.persee.fr/web/revues/home/prescript/article/pica_07525656_2002_num_1_1_2308 [consulta: 18/07/12]

Collardelle, M, Verdel, E., 1993. Les habitats du lac de Paladru dans leur environnement. La formation d'un terroir au Xle siècle. Editions de la Maison des Sciences de l'Homme, Paris. Documents d'Archéologie française 40

Cosín Corral, Y, García Aparicio, C., 1998. Alquerque, mancala y dados. Juegos musulmanes en la ciudad de Vascos. Revista de Arqueología 201, 38-47.

Dedies, D., Sarret, J.-P., 1981. Jeux et divertissements. In: Montsègur. 13 ans de recherche archeologique, 1964-1976, 217-221. La recherche archèologique à Montsègur, 4e année. Numéro spécial 1980, Groupe de recherches archèologique à Montsègur et environs, Carcassonne.

Diderot et D'Alambert, 1771. Recueil de planches sur les sciences, les arts liberaux et les arts mechaniques avec leur explication. Vol. VIII. Briasson edit. Paris. Available from : http:// planches.eu/PLANCHES08.pdf [consulta : 20/07/12].

Domínguez Fernández, E., Elía Munarriz, A., 1993 . Juegos de azar en la Navarra medieval. En: XI jornades d'Estudis Històrics Locals. Espai i temps d'oci a la historia (Palma, del 14 al 17 de desembre de 1992), 601-615. Govern Balear, Palma.

Espinar Moreno, M., Domínguez Bedmar, M., 1987. Un dado islámico procedente del cerro del castillo (Albox, Almería). En: Actas del II Congreso de Arqueología Medieval Española t. II, 603-606. Madrid.

Fagniez, G., 1898. Documents relatif à l'histoire et du commerce en France. A. Picard et fils, Paris. T. I. Available from: http://catalogue.bnf.fr/ark:/12148/cb30415509z [consulta: $18 / 07 / 12]$

Lassure, J.-M., 1998. La civilisation matérielle de la Gascogne aux XIle et XIIle siècles. Le mobilier du site archéologique de Corné à L'Isle-Bouzon (Gers). Université de Toulouse-Le Mirail.

López Mendizábal, I., 1959. Un nuevo castillo medieval en Guipúzcoa. Boletín Real Sociedad Bascongada Amigos del País XV (1), 61-65.
López Padilla, J.A., 2010. Dos instrumentos de asta de ciervo localizados en el Castell de Castalla. En: Menéndez Fueyo, J.L., Bevià i García, M., Mira Rico, J.A., Ortega Pérez, J.R. (Eds.), El Castell de Castalla. Arqueología, arquitectura e historia de una fortificación medieval de frontera, 183-188. MARQ. Museo Arqueológico Provincial de Alicante.

MacGregor, A., 1985. Bone, Antler, Ivory and Horn: the Technology of Skeletal Materials since the Roman period. Croom Helm, Londres.

Mehl, J.-M., 1990. Les jeux au royaume de France du XIIle au debut du XVle siècle. Fayard, Paris.

Menéndez-Pidal, G., 1984. La España del siglo XIII leída en imágenes. Cuadernos de la Alhambra 19-20, 3-57.

Molina Molina, A. L., 1999. El juego de dados en la Edad Media. Murgetana 100, 95-104.

Musser, S., 2007. Los libros de acedrex dados e tablas: Historical, Artistic and Metaphysical Dimensions of Alfonso X's Book of Games. Tesis doctoral, The University of Arizona. Available from: http://hdl.handle.net/10150/194159 [consulta: 20/07/12].

Padilla Lapuente, J.I., 1992-7. Fortificación medieval de Mendikute (Albiztur). Arkeoikuska 92, 211-227; 93, 197-213; 94, 185-203; 95,187-211; 96, 99-107; 97, 145-152. [Informes de campaña].

Padilla Lapuente, J.I., 1999-4. Fortaleza medieval de Ausa Gaztelu (Zaldibia). Arkeoikuska 99, 107-113; 00, 99-105; 01, 134-139; 02, 123-127; 03, 123-127; 04, 129-134. [Informes de campaña].

Padilla Lapuente, J.I., Álvaro Rueda, k., 2010. El sonido de la guerra: las trompas de la fortaleza medieval de Ausa (Zaldibia, Gipuzkoa). Acta Historica et Archaeologica Medievalia, 30, 453-485.

Ramos Agirre, M., 1984. Gorriti en la historia. Desde los documentos escritos y los datos arqueológicos. En: El castillo de Gorriti. Un pueblo recupera su memoria (L. Zavala Fernández de Heredia, edit.). Basauri. Available from: http://www.archivozavala.org/Castillo_gorriti/GORRITI-b.pdf [consulta: 17/07/12]

Sarasola Etxegoien, N., 2011. El poblamiento medieval de Gipuzkoa. Revisión crítica del registro arqueológico. Munibe Antropologia-Arkeologia 61, 339-393.

Viure a palau a l'Edat Mitjana, segles XII-XV. Catàleg d'exposició, 2004. Centro Cultural de Caixa de Girona (16 juliol al 19 de setembre). Girona.

Wickham, C., 2004. Sobre la mutación socioeconómica de larga duración en occidente durante los siglos V-VIII. Studia Historica, Historia Medieval 22, 17-32.

Wickham, C., 2005. Framing the Early Middle Ages. Europe and the Mediterranean, 400-800. Oxford University Press, Oxford.

Zozaya, J., 1995. Dados. En: Zozaya, J. (Ed.), Alarcos. El fiel de la balanza, Catálogo Exposición Ciudad Real, 193. Servicio de Publicaciones de la Junta de Comunidades de Castilla-La Mancha, Toledo. 